\title{
Três percepções sobre gestação e puerpério
}

\author{
César Eduardo Fernandes \\ Disciplina de Ginecologia, Faculdade de Medicina do ABC (FMABC), Santo André (SP), Brasil. \\ E-mail: cesar.fernandes@fmabc.br
}

DOI: http://dx.doi.org/10.7322/abcshs.v40i2.731

A presente edição da ABCS Health Sciences traz três artigos relacionados à gravidez e ao puerpério. Um deles aborda as percepções de puérperas adolescentes relacionadas ao pré-natal e ao parto; os outros dois tratam da satisfação com a imagem corporal em mulheres gestantes e não gestantes e da avaliação da sexualidade de gestantes durante o terceiro trimestre gestacional.

O artigo de Luz e colaboradores ${ }^{1}$ analisa um tema pouco considerado em trabalhos acadêmicos, em especial, entre nós. Cabe lembrar que para algumas adolescentes, a gravidez e o parto são planejados e desejados. No entanto, para muitas, especialmente no Brasil, a gravidez e o parto ocorrem de maneira não planejada, criando uma atmosfera inóspita, não raro com desaprovação familiar e sem o apoio do parceiro, aumentando ainda mais a vulnerabilidade desta população especial, já naturalmente fragilizada, num momento tão desafiador.

Os autores, usando metodologia de entrevistas com abordagem qualitativa, em uma maternidade de Jataí-GO, conseguiram depoimentos de 11 puérperas, com idades entre 12 e 19 anos, todas primíparas, que deram a luz através de parto vaginal com feto único a termo. A análise se deu em dois momentos, no transcurso do pré-natal e na assistência ao parto. Conseguiram demonstrar que as adolescentes consideraram o atendimento e assistência recebida durante o pré-natal e trabalho de parto satisfatório, devido às orientações e à atenção prestadas pela equipe de saúde. No entanto, foram relatadas situações de violência obstétrica com um atendimento desumanizado e humilhante por parte de algumas adolescentes.

A demonstração destes casos de atendimentos insatisfatórios e degradantes nos chamam atenção para uma realidade que, infelizmente, ainda existe em nosso país e, que precisa mudar rapidamente. Parece claro que resolução dos problemas de cuidados pré-natais e de assistência ao parto de adolescentes não está centrada em avanços estruturais ou em sofisticação tecnológica e sim, na melhoria de atitudes e comportamentos dos trabalhadores da saúde que, efetivamente, contribuam para o fortalecimento do vínculo entre profissionais, usuárias, família e comunidade. Por esta razão, emerge desta publicação que o mais importante é que os profissionais de saúde tenham sensibilidade para compreender a adolescente nas suas particularidades, respeitando seus valores, sua cultura e suas opções, prestando uma assistência qualificada, individualizada e mais humana. ${ }^{2,3}$ Existe uma necessidade urgente de mudança de modelos de atendimento e de educação dos profissionais de saúde acompanhadas de uma melhoria de suas condições de trabalho que, não raro, são precárias em praticamente todo o país.

Os outros dois artigos, Teixeira et al. ${ }^{4}$ e Mathias et al. ${ }^{5}$, publicados por dois grupos distintos, respectivamente da Universidade de Pernambuco (UPE) e da Universidade do Estado de Santa Catarina (UDESC), guardam relação entre si. O padrão ideal de silhueta das gestantes e mesmo das não gestantes não parece ser o que estão vivenciando ${ }^{4}$. A maioria das mulheres participantes do estudo de avaliação da imagem corporal acredita que a silhueta ideal deve ser mais magra do que a silhueta atual que apresentam. Quanto às gestantes fica claro que têm percepção de sua mudança corporal ao longo da gravidez ainda que objetivem um retorno à imagem corporal prévia à gestação com pouca alteração em relação ao perfil não-grávido. Sobre a avaliação das disfunções sexuais no terceiro trimestre gestacional, o estudo pode demonstrar uma taxa moderada de disfunção sexual de maneira global em todos os domínios analisados ${ }^{5}$.

É interessante notar a proximidade destes dois estudos. Claro, existem múltiplas razões apontadas pelas mulheres para o comprometimento da sua sexualidade ao longo da gravidez. A fadiga, o desconforto físico (incluindo a dispareunia) e a preocupação com o bem-estar fetal são, em geral, os mais relatados. Existem, no entanto, outros fatores que se juntam a estes e que também podem condicionar a sexualidade do casal. A dificuldade no coito pelo abdome proeminente da grávida e a diminuição da autoestima da mulher devido à imagem corporal ${ }^{6-8}$ parecem ter grande relevância para a redução da atividade sexual apontada no estudo sobre a disfunção sexual de gravidas no transcurso do terceiro trimestre. Neste ponto é que os dois artigos publicados na edição atual encontram convergência e merecem ser analisados conjuntamente. Creio tratar-se de contribuição relevante ao conhecimento do comportamento das gestantes e de sua autopercepção em relação à imagem corporal e sexualidade. 


\section{REFERÊNCIAS}

1. Luz NF, Assis TR, Rezende FR. Puérperas adolescentes: Percepções relacionadas ao pré-natal e ao parto. ABC Health Sci. 2015;40(2):80-4

http://dx.doi.org/10.7322/abcshs.v40i2.735

2. Santos DR, Maraschin MS, Caldeira S. Percepção dos enfermeiros frente à gravidez na adolescência. Ciênc Cuid Saúde. 2007;6(4):479-85.

http://dx.doi.org/10.4025/cienccuidsaude.v6i4.3684

3. Damiane FE. Gravidez na adolescência: a quem cabe prevenir? Rev Gaúcha Enfermagem. 2003;24(2):161-8.

4. Teixeira FA, Schneider VLP, Wolpe RE, Sperandio FF. Satisfação com a imagem corporal em mulheres gestantes e não gestantes. ABC Health Sci. 2015;40(2):69-74.

http://dx.doi.org/10.7322/abcshs.v40i2.733
5. Mathias AERA, Pitangui ACR, Arantes VA, Freitas HGV, Vilela FMF, Dias TG. Disfunção sexual: Avaliação de mulheres durante o terceiro trimestre gestacional. ABC Health Sci. 2015;40(2):75-9. http://dx.doi.org/10.7322/abcshs.v40i2.734

6. Masters WH, Johnson VE. Human sexual response. Londres: Churchill Livingston; 1966.

7. Bartellas E, Crane JM, Daley M, Bennett KA, Hutchens D. Sexuality and sexual activity in pregnancy. BJOG 2000;107(8):964-8. http://dx.doi.org/10.1111/j.1471-0528.2000.tb10397.x

8. Oruç $S$, Esen $A$, Lacin $S$, Adigüzel $H$, Uyar $Y$, Koyuncu $F$. Sexual behavior during pregnancy. Aust N Z J Obstet Gynaecol 1999;39(1):48-50. 